\title{
Identify Prognostic Factors and Establish a Risk Stratification Model to Predict Cancer-Specific Survival for Patients with Pancreatic Cancer Liver Metastasis: A Population-Based Study
}

\section{Biyang Cao}

The First Medical Center of Chinese PLA General Hospital

Chenchen Wu

The First Medical Center of Chinese PLA General Hospital

\section{Letian Zhang}

The First Medical Center of Chinese PLA General Hospital Jing Wang ( $\nabla$ cao18383042336@outlook.com)

The First Medical Center of Chinese PLA General Hospital

\section{Research Article}

Keywords: Liver metastases, Pancreatic cancer, Prognosis, Survival, SEER

Posted Date: September 29th, 2021

DOl: https://doi.org/10.21203/rs.3.rs-855925/v1

License: (c) (1) This work is licensed under a Creative Commons Attribution 4.0 International License.

Read Full License 


\section{Abstract \\ Background}

Pancreatic cancer liver metastasis (PCLM) is a commonly fatal disease, but there are few prognostic models for these entities. The purpose of this study is to investigate prognostic factors based on clinicopathological characteristics and establish a prognostic nomogram predicting the cancer-specific survival (CSS) for PCLM patients.

\section{Methods}

The characteristics of 6015 patients with PCLM between 2010 and 2015 from Surveillance, Epidemiology, and End Results (SEER) database were analyzed. Prognostic factors and nomogram predicting CSS were developed by Cox proportional hazard regression model. The predictive accuracy and discriminative ability of nomogram were assessed by concordance index (C-index), calibration curve, decision curve analyses (DCAs) and receiver operating characteristic (ROC) curve. Moreover, a risk classification system was built according to the cut-off values off the nomogram.

\section{Results}

Based on the univariate and multivariate Cox regression analysis, significant prognostic factors were identified and included to establish the nomogram for CSS. The median survival time (MST) for all patients is 4.0 months ( $95 \%$ confidence interval [CI]:3.8-4.2) and CSS at 6,12 and 18 months was $34.12 \%, 15.63 \%$ and $7.83 \%$, respectively. The C-index of nomogram was 0.693 (95\% Cl: $0.689-0.697$ ) and all verification results showed an accurate and discriminative ability in predicting CSS. Significant differences in Kaplan-Meier curves were observed in patients stratified into different risk groups $(\mathrm{p}<$ 0.001), with MST of 7.0 months (95\% Cl: 6.7-7.3), 3.0 months (95\% Cl: $2.7-3.3)$, and 2.0 months (95\% Cl: 1.8-2.2), respectively.

\section{Conclusions}

A prognostic nomogram and corresponding risk classification system were proposed to predict CSS for PCLM.

\section{Background}

Pancreatic cancer (PC) is the 12th most commonly diagnosed cancer and the 7th leading cause of cancer-related death in both men and women worldwide, with an estimated 496,000 new cases and 466,000 deaths according to GLOBOCAN 2020[1]. Despite tremendous advances in the molecular understanding and systemic therapies for PC, the prognosis for this disease remains dismal, with overall 
5-year survival rates of $8-10 \%$ and a median survival period of less than 1 year after diagnosis[2]. A major factor associated with the poor outcomes in these patients is the difficulty of early diagnosis. Due to the absence of specific symptoms and effective, sensitive screening methods or biomarkers, the vast majority $(>80 \%)$ of patients are diagnosed at a late stage, characterized by locally advanced $(\sim 30 \%)$ or metastatic (> 50\%) disease[3]. Distant metastasis is a major indicator of poor prognosis, as once distant metastases occur, radical surgery, which is deemed as the only potentially curative therapy, is not available[4, 5]. Compared with patients with localized tumors, the survival of patients with metastasis is only 3-6 months[6]. PC remains one of the most lethal malignancies, partly owing to its aggressive biology characterized by early metastatic nature. Liver metastasis is the most common pattern of metastasis and is the leading cause of death for PC [7]. More than half of PC patients present with synchronous liver metastatic disease on an initial presentation[8]. Even these patients who have undergone curative operation will develop metachronous liver metastasis within 2 to 4 years after pancreatectomy due to the present micrometastasis indeed [3, 7]. Patients with liver metastasis have even worse prognosis than those with lung metastasis or other distant metastases [9]. The median survival time (MST) in patients of PCLM is less than half a year because of its refractory course and rapid progress[10]. Most patients with PCLM are referred to systematic chemotherapy or best supportive care, and chemotherapy remains the mainstay of treatment. Recent years have witnessed the development of new therapeutic drugs and more effective chemotherapy regimens; the MST of patients with PCLM has been prolonged to 6-10 months[11]. However, the survival benefit is limited to a few strictly selected patients with a favorable performance status[12]. Thus, PCLM is a commonly fatal disease and has an extremely poor prognosis, identification of predictive and prognostic factors and evaluating novel treatment strategies are equally crucial to improve the prognosis. The most commonly used staging system for predicting prognosis is the TNM classification system, based on the size and extent of the tumor $(T)$, the number of positive lymph nodes $(N)$ and distant metastasis $(M)$. For PCLM, patients are broadly grouped into same stage cohorts (stages IV) with assumed homogenous outcomes. However, in fact, outcomes are quite heterogeneous as a result of variability in clinicopathologic features and tumor biology within these patients. Therefore, the predictive accuracy of the TNM staging system is limited and a comprehensive prognostic model is needed to accurately evaluate the prognosis of each patient. A nomogram is a useful and accessible tool and has been developed in the majority of cancers for physicians to predict survival. Nomogram prognostic models that provide an individualized outcome prediction may facilitate better personalized treatment and risk stratification[13]. He et al[14] constructed a nomogram to predict liver metastasis in PC patients based on clinicopathological factors, in order to improve the prediction of the risks of liver metastasis among them before preclinical metabolism. However, in the real-world treatment, liver metastasis is hardly evitable due to the refractory course and rapid progress. Considering the current desperate state of overall survival and there has been not prior studies building prognostic model for these entities, we primarily focus on clinical outcomes and prognosis of PCLM under real-world treatment patterns. To our knowledge, this study is the first attempt to establish a prognostic nomogram for PCLM based on clinicopathologic data of a large cohort of patients, in order to provide more-accurate prediction of survival and could aid clinicians and patients in the treatment decision-making process. 


\section{Methods}

\subsection{Population Selection}

The SEER database collects cancer incidence data from a population-based cancer registry covering approximately $34.6 \%$ of the U.S. The SEER registry collects data on patient demographics, primary tumor site, tumor morphology, stage at diagnosis and first course of treatment, and follow-up on patient vital status. A total of 6,015 patients with a histological diagnosis of PCLM between 2010 and 2015 were

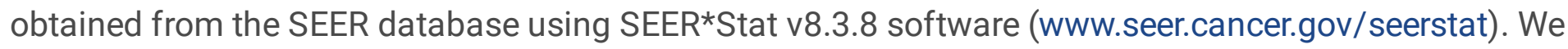
obtained a license to analyze the study data in November 2020 (username: 21819-Nov2019). In our study, patients were selected based on the following inclusion and exclusion criteria. Inclusion criteria included the following. (1) PC patients diagnosed between 2010 and 2015; (2) combined liver metastases; (3) International Classification of Diseases for Oncology, Third Revision (ICD-O-3), histology codes: 8010,8140,8500; and (4) With "cancer-specific death " classification (alive or dead due to this cancer). Exclusion criteria were as follows. (1) non-primary tumor; (2) age < 18 years at diagnosis; (3) patients without pathological diagnosis; (4) survival < 1 month; (5) missing or incomplete information on treatment, follow-up, tumor size, and other characteristics; and (6) unknown status of liver, lung, bone, or brain metastases. All included PCLM patients were randomly divided into a training set $(70 \%)$ and an internal validation set (30\%). The training set was used to identify independent prognostic factors and create a prognostic nomogram for PCLM patients, while the internal validation set was used to validate the nomogram.

\subsection{Variables and Definition of endpoint}

Data on patients' demographic characteristics (age at diagnosis, sex, race, and marital status), disease features of tumors (histologic grade, primary site, distant metastatic site, T stage, lymph nodes metastases, number of metastatic organs), clinical treatment information (surgery, radiotherapy, and chemotherapy), survival data (follow-up time, survival status and cause of death) were extracted and analyzed from SEER database. Age and tumor size, as a continuous variable, were divided into groups, and the best cutoff values were calculated by the X-tile software (Yale School of Medicine, New Haven, CT, USA) for outcome-based optimization. In our research, the primary endpoint was CSS, which was defined as the time from the time of initial diagnosis to cancer-specific death.

\subsection{Statistical Analysis}

Patient baseline characteristics between the cohorts were compared by chi-square test. Univariate analysis was performed to identify the independent effects of each prognostic factors on CSS. The statistically meaningful $(p<0.05)$ factors in univariate analysis were further taken into the multivariable Cox analysis using a backwards model selection procedure (elimination criterion: $p>0.1$ ). Multivariate Cox regression analyses were performed to identify the independent prognostic factors for PCLM patients. The nomogram and risk classification system were built based on the statistically significant factors selected in multivariate analysis. Kaplan-Meier survival curves were plotted to estimate the CSS 
and log-rank test was used to assess the significant differences in survival. The predictive parameters of this nomogram, including predictive accuracy and calibration, were evaluated in the training and validation cohort. C-index and the AUC values were used to measure the discrimination ability of the nomogram. Calibration curves were plotted to evaluated the consistency between actual outcome and predicted probabilities. DCAs was used to show the clinical usefulness of the nomogram. All statistical analyses were performed with R software (version 4.0.1; http://www.r-project.org) and SPSS statistics software (version 26; IBM Corp, Armonk, NY, USA). A two-tailed P value $<0.05$ was considered statistically significant.

\section{Results}

\subsection{Patient Characteristics}

As shown in Fig. 1, a total of 6015 eligible patients, histologically diagnosed with PCLM between 2010 and 2015 in the SEER database were enrolled and analyzed in the study. The demographic and clinical characteristics of all patients are demonstrated in Table 1. The median age of whole cohorts was 65 years and the median follow-up time was 4 months (range: 1-77 months). All eligible cases were randomly assigned to the training $(4210,70 \%)$ and validation cohorts $(1805,30 \%)$. By the time of followup, cancer-specific death had occurred in 5620/6015 (93.4\%), 3922/4210 (93.1\%), and 1738/1805 (96.3\%) patients among the total, training, and validation cohorts, respectively. The median CSS was 4.0 months (95\% confidence interval [Cl] 3.8-4.2), 4.0 months (95\% Cl 3.8-4.2), and 4.0 months $(95 \% \mathrm{Cl} 3.7-$ 4.3 ) in the total, training, and validation cohorts, respectively (log-rank test, training vs. validation cohort: $p=0.958$ ). There was no significant difference in the baseline characteristics between the training and validation cohorts (Table 1). 
Table 1

Baseline clinicopathological characteristics and treatment experience of all patients and those in the training and validation cohort

\begin{tabular}{|c|c|c|c|c|}
\hline Characteristic & $\begin{array}{l}\text { All cohorts } \\
(\mathrm{N}=6015)\end{array}$ & $\begin{array}{l}\text { Training cohort } \\
(\mathrm{N}=4210)\end{array}$ & $\begin{array}{l}\text { Validation cohort } \\
(\mathrm{N}=1805)\end{array}$ & p. value ${ }^{a}$ \\
\hline Age (years) & & & & 0.598 \\
\hline$<60$ & $1824(30.3 \%)$ & $1289(30.6 \%)$ & $535(29.6 \%)$ & \\
\hline $60-80$ & 3681 (61.2\%) & 2559 (60.8\%) & $1122(62.2 \%)$ & \\
\hline$>80$ & $510(8.48 \%)$ & 362 (8.60\%) & $148(8.20 \%)$ & \\
\hline Sex & & & & 0.518 \\
\hline Female & 2709 (45.0\%) & 1908 (45.3\%) & 801 (44.4\%) & \\
\hline Male & 3306 (55.0\%) & 2302 (54.7\%) & 1004 (55.6\%) & \\
\hline Race & & & & 0.564 \\
\hline White & $4751(79.0 \%)$ & 3338 (79.3\%) & $1413(78.3 \%)$ & \\
\hline Black & 849 (14.1\%) & 581 (13.8\%) & $268(14.8 \%)$ & \\
\hline Other & 415 (6.90\%) & 291 (6.91\%) & $124(6.87 \%)$ & \\
\hline Marital status & & & & 0.124 \\
\hline Married & 3493 (58.1\%) & 2409 (57.2\%) & $1084(60.1 \%)$ & \\
\hline Unmarried & 2291 (38.1\%) & 1636 (38.9\%) & 655 (36.3\%) & \\
\hline Unknow & 231 (3.84\%) & 165 (3.92\%) & 66 (3.66\%) & \\
\hline Primary site & & & & 0.409 \\
\hline Head & 2306 (38.3\%) & 1596 (37.9\%) & 710 (39.3\%) & \\
\hline Body & 1093 (18.2\%) & 774 (18.4\%) & 319 (17.7\%) & \\
\hline Tail & 1474 (24.5\%) & 1052 (25.0\%) & $422(23.4 \%)$ & \\
\hline Other & $1142(19.0 \%)$ & 788 (18.7\%) & $354(19.6 \%)$ & \\
\hline Histologic grade & & & & 0.968 \\
\hline Grade I-II & 655 (10.9\%) & $456(10.8 \%)$ & $199(11.0 \%)$ & \\
\hline
\end{tabular}

LNLymph Node, ${ }^{\text {a }}$ Chi square test

* Metastatic burden is classified by the number of metastatic sites

Surgery is specifically referred to the surgery to primary site of malignant tumor 


\begin{tabular}{|c|c|c|c|c|}
\hline Characteristic & $\begin{array}{l}\text { All cohorts } \\
(N=6015)\end{array}$ & $\begin{array}{l}\text { Training cohort } \\
(\mathrm{N}=4210)\end{array}$ & $\begin{array}{l}\text { Validation cohort } \\
(\mathrm{N}=1805)\end{array}$ & p. value ${ }^{a}$ \\
\hline Grade III-IV & $786(13.1 \%)$ & $552(13.1 \%)$ & $234(13.0 \%)$ & \\
\hline Unspecific & $4574(76.0 \%)$ & 3202 (76.1\%) & $1372(76.0 \%)$ & \\
\hline T stage & & & & 0.191 \\
\hline T1 & $326(5.4 \%)$ & $234(5.6 \%)$ & $92(5.1 \%)$ & \\
\hline T2 & 2362(39.3\%) & 1671 (39.7\%) & $691(38.3 \%)$ & \\
\hline Т3 & 2474(41.1\%) & 1697 (40.3\%) & 777(43.0\%) & \\
\hline T4 & $853(14.2 \%)$ & $608(14.4 \%)$ & $245(13.6 \%)$ & \\
\hline LN metastasis & & & & 0.746 \\
\hline Absent & 3712 (61.7\%) & $2592(61.6 \%)$ & $1120(62.0 \%)$ & \\
\hline Present & $2303(38.3 \%)$ & 1618 (38.4\%) & $685(38.0 \%)$ & \\
\hline Tumor size (cm) & & & & 0.711 \\
\hline$\leq 4.4$ & 3499 (58.2\%) & $2456(58.3 \%)$ & 1043 (57.8\%) & \\
\hline$>4.4$ & $2516(41.8 \%)$ & 1754 (41.7\%) & $762(42.2 \%)$ & \\
\hline Bone metastasis & & & & 0.727 \\
\hline No & $5673(94.3 \%)$ & 3974 (94.4\%) & 1699 (94.1\%) & \\
\hline Yes & $342(5.69 \%)$ & $236(5.61 \%)$ & 106 (5.87\%) & \\
\hline Brain metastasis & & & & 0.388 \\
\hline No & 5986 (99.5\%) & 4190 (99.5\%) & 1796 (99.5\%) & \\
\hline Yes & $29(0.48 \%)$ & $20(0.48 \%)$ & $9(0.50 \%)$ & \\
\hline Lung metastasis & & & & 0.456 \\
\hline No & 5085 (84.5\%) & 3549 (84.3\%) & 1536 (85.1\%) & \\
\hline Yes & $930(15.5 \%)$ & 661 (15.7\%) & 269 (14.9\%) & \\
\hline Metastatic burden ${ }^{\star}$ & & & & 0.983 \\
\hline 1 & $4856(80.7 \%)$ & 3395 (80.6\%) & 1461 (80.9\%) & \\
\hline \multicolumn{5}{|c|}{ LN Lymph Node, ${ }^{\text {a }}$ Chi square test } \\
\hline \multicolumn{5}{|c|}{ * Metastatic burden is classified by the number of metastatic sites } \\
\hline Surgery is specifical & referred to the & rgery to primar & te of malignant ti & \\
\hline
\end{tabular}




\begin{tabular}{|c|c|c|c|c|}
\hline Characteristic & $\begin{array}{l}\text { All cohorts } \\
(N=6015)\end{array}$ & $\begin{array}{l}\text { Training cohort } \\
(\mathrm{N}=4210)\end{array}$ & $\begin{array}{l}\text { Validation cohort } \\
(\mathrm{N}=1805)\end{array}$ & p. value ${ }^{a}$ \\
\hline 2 & $1022(17.0 \%)$ & $717(17.0 \%)$ & $305(16.9 \%)$ & \\
\hline 3 & $132(2.19 \%)$ & $94(2.23 \%)$ & $38(2.11 \%)$ & \\
\hline$\geq 4$ & $5(0.08 \%)$ & $4(0.10 \%)$ & $1(0.06 \%)$ & \\
\hline Surgery* & & & & 0.501 \\
\hline No & $5830(96.9 \%)$ & $4081(96.9 \%)$ & $1749(96.9 \%)$ & \\
\hline Yes & $185(3.08 \%)$ & $129(3.06 \%)$ & $56(3.10 \%)$ & \\
\hline Radiation & & & & 0.366 \\
\hline No & $5748(95.6 \%)$ & $4016(95.4 \%)$ & $1732(96.0 \%)$ & \\
\hline Yes & $267(4.44 \%)$ & $194(4.61 \%)$ & $73(4.04 \%)$ & \\
\hline Chemotherapy & & & & 0.465 \\
\hline No & $1944(32.3 \%)$ & $1348(32.0 \%)$ & $596(33.0 \%)$ & \\
\hline Yes & $4071(67.7 \%)$ & $2862(68.0 \%)$ & $1209(67.0 \%)$ & \\
\hline \multicolumn{5}{|c|}{ LN Lymph Node, ${ }^{\text {a }}$ Chi square test } \\
\hline \multicolumn{5}{|c|}{ * Metastatic burden is classified by the number of metastatic sites } \\
\hline
\end{tabular}

\subsection{Univariate and Multivariate Analyses and Identification of Prognostic Factors}

The Cox proportional hazards model was used in the training cohort to select significant prognostic clinicopathological factors for constructing a nomogram predicting CSS. According to the univariate and multivariate Cox regression analyses for the training cohort, age at diagnosis, primary site, histologic grade, $\mathrm{T}$ stage, tumor size, number of metastatic organs, and surgery to primary site, radiation, chemotherapy were identified as independent prognostic factors of CSS (Table 2). Figure 2 provides the forest plot analysis of prognostic factors associated with CSS in detail. 
Table 2

Univariate and multivariate cox progression of CSS of pancreatic cancer patients with initial liver metastasis

\begin{tabular}{|c|c|c|c|c|}
\hline \multirow[t]{2}{*}{ Characteristic } & \multicolumn{2}{|c|}{ Univariate analysis } & \multicolumn{2}{|c|}{ Multivariate analysis } \\
\hline & $\mathrm{HR}(95 \% \mathrm{Cl})$ & $\mathbf{P}$ & $\mathrm{HR}(95 \% \mathrm{Cl})$ & $\mathbf{P}$ \\
\hline \multicolumn{5}{|l|}{ Age (years) } \\
\hline \multicolumn{5}{|l|}{$<60$} \\
\hline $60-80$ & $1.28(1.2-1.35)$ & $<0.001$ & $1.22(1.15,1.30)$ & $<0.001$ \\
\hline$>80$ & $2.11(1.91-2.34)$ & $<0.001$ & $1.61(1.45,1.79)$ & $<0.001$ \\
\hline \multicolumn{5}{|l|}{ Sex } \\
\hline \multicolumn{5}{|l|}{ Female } \\
\hline Male & $1.02(0.97-1.08)$ & 0.364 & & \\
\hline \multicolumn{5}{|l|}{ Race } \\
\hline \multicolumn{5}{|l|}{ White } \\
\hline Black & $1.07(1.00-1.16)$ & 0.063 & & \\
\hline Other & $1.08(0.97-1.20)$ & 0.164 & & \\
\hline \multicolumn{5}{|l|}{ Marital status } \\
\hline \multicolumn{5}{|l|}{ Married } \\
\hline Unmarried & $1.26(1.2-1.33)$ & $<0.001$ & $1.13(1.07,1.20)$ & 0.056 \\
\hline Unknow & $1.12(0.97-1.28)$ & 0.112 & $1.03(0.89,1.18)$ & 0.697 \\
\hline \multicolumn{5}{|l|}{ Primary site } \\
\hline \multicolumn{5}{|l|}{ Head } \\
\hline Body & $1.02(0.95-1.10)$ & 0.63 & $0.99(0.91,1.07)$ & 0.748 \\
\hline Tail & $1.14(1.06-1.21)$ & $<0.001$ & $1.12(1.05,1.21)$ & 0.001 \\
\hline Other & $1.15(1.07-1.24)$ & $<0.001$ & $1.03(0.96,1.12)$ & 0.379 \\
\hline \multicolumn{5}{|c|}{ Histologic grade } \\
\hline \multicolumn{5}{|l|}{$\mid-I I$} \\
\hline III-IV & $1.40(1.25-1.55)$ & $<0.001$ & $1.38(1.24,1.54)$ & $<0.001$ \\
\hline Unspecific & $1.35(1.24-1.47)$ & $<0.001$ & $1.24(1.13,1.35)$ & $<0.001$ \\
\hline
\end{tabular}

CSS cancer-specific survival, LN Lymph Node, HR hazard ratio, Cl confidence interval 


\begin{tabular}{|c|c|c|c|c|}
\hline \multirow[t]{2}{*}{ Characteristic } & \multicolumn{2}{|c|}{ Univariate analysis } & \multicolumn{2}{|c|}{ Multivariate analysis } \\
\hline & $\mathrm{HR}(95 \% \mathrm{Cl})$ & $\mathbf{P}$ & $\mathrm{HR}(95 \% \mathrm{Cl})$ & $P$ \\
\hline \multicolumn{5}{|l|}{ T stage } \\
\hline \multicolumn{5}{|l|}{ T1 } \\
\hline T2 & $1.09(0.96-1.23)$ & 0.172 & $1.10(0.97-1.23)$ & 0.131 \\
\hline T3 & $1.24(1.10-1.40)$ & 0.001 & $1.13(1.01-1.31)$ & 0.041 \\
\hline T4 & $0.98(0.86-1.12)$ & 0.751 & $0.99(0.86-1.14)$ & 0.868 \\
\hline \multicolumn{5}{|l|}{ LN metastasis } \\
\hline \multicolumn{5}{|l|}{ Absent } \\
\hline Present & $1.03(0.97-1.08)$ & 0.364 & & \\
\hline \multicolumn{5}{|c|}{ Tumor size (cm) } \\
\hline \multicolumn{5}{|l|}{$\leq 4.4$} \\
\hline$>4.4$ & $1.14(1.08-1.20)$ & $<0.001$ & $1.17(1.08,1.28)$ & $<0.001$ \\
\hline \multicolumn{5}{|c|}{ Bone metastasis } \\
\hline \multicolumn{5}{|l|}{ No } \\
\hline Yes & $1.33(1.19-1.49)$ & $<0.001$ & $0.96(0.67,1.38)$ & 0.829 \\
\hline \multicolumn{5}{|c|}{ Brain metastasis } \\
\hline \multicolumn{5}{|l|}{ No } \\
\hline Yes & $2.07(1.42-3)$ & $<0.001$ & $1.51(0.98,2.33)$ & 0.059 \\
\hline \multicolumn{5}{|c|}{ Lung metastasis } \\
\hline \multicolumn{5}{|l|}{ No } \\
\hline Yes & $1.34(1.25-1.45)$ & $<0.001$ & $0.86(0.60,1.23)$ & 0.414 \\
\hline \multicolumn{5}{|c|}{ Metastatic burden } \\
\hline \multicolumn{5}{|l|}{1} \\
\hline 2 & $1.34(1.25-1.43)$ & $<0.001$ & $1.47(1.03,2.11)$ & 0.035 \\
\hline 3 & $1.60(1.34-1.90)$ & $<0.001$ & $1.94(0.94,3.97)$ & 0.071 \\
\hline$\geq 4$ & $1.18(0.44-3.16)$ & 0.735 & NA (NA, NA) & NA \\
\hline
\end{tabular}

CSS cancer-specific survival, LNLymph Node, HR hazard ratio, C/ confidence interval 


\begin{tabular}{|c|c|c|c|c|}
\hline \multirow[t]{2}{*}{ Characteristic } & \multicolumn{2}{|c|}{ Univariate analysis } & \multicolumn{2}{|c|}{ Multivariate analysis } \\
\hline & $\mathrm{HR}(95 \% \mathrm{Cl})$ & $\mathbf{P}$ & $\mathrm{HR}(95 \% \mathrm{Cl})$ & $\mathbf{P}$ \\
\hline \multicolumn{5}{|l|}{ No } \\
\hline Yes & $0.47(0.4-0.56)$ & $<0.001$ & $0.46(0.39,0.54)$ & $<0.001$ \\
\hline \multicolumn{5}{|l|}{ Radiation } \\
\hline \multicolumn{5}{|l|}{ No } \\
\hline Yes & $0.83(0.73-0.94)$ & 0.004 & $0.87(0.76,0.98)$ & 0.028 \\
\hline \multicolumn{5}{|l|}{ Chemotherapy } \\
\hline \multicolumn{5}{|l|}{ No } \\
\hline Yes & $0.38(0.36-0.4)$ & $<0.001$ & $0.38(0.36,0.40)$ & $<0.001$ \\
\hline
\end{tabular}

\subsection{Constructing and Validating the Novel Nomogram}

Based on independent prognostic factors associated with CSS, a nomogram including age at diagnosis, primary site, histologic grade, T stage, tumor size, number of metastatic organs, and surgery to primary site, radiation, chemotherapy, was performed to predict a 6-, 12- and 18-month CSS rate. These factors are virtually displayed and assigned with a corresponding number of points according to the regression coefficient in the form of the nomogram. An individual probability of a clinical event is generated by integrating diverse prognostic factors and calculating total number of points for each patient according to the nomogram. The prognostic nomogram was virtually presented in Fig. 3, and was validated using the validation cohort. The C-index of the novel nomogram was 0.693 (95\% Cl: $0.689-0.697)$ and the 6-, 12- and 18-month AUC values from time-dependent ROC curve of the training group were $0.747,0.725$ and 0.713 , respectively; while the corresponding AUC values in the validation group were $0.736,0.718$, and 0.711 , respectively, reflecting medium accuracy and discriminative ability in predicting the CSS (Fig.

4A-B). The calibration curves also suggested good consistency in the probability of 6-, 12-, and 18-month CSS between prediction and observation in training cohort (Fig. 4C-E). Additionally, the DCAs exhibited great positive net benefits for all patients when predicting the 6-, 12-and 18-month CSS rates, indicating the favorable potential clinical value of the predictive model (Fig. 4F-H).

\subsection{Cancer-Specific Survival and Risk Classification System}

In the present study, the MST for all PCLM patients is 4 months and CSS at 6, 12 and 18 months of these patients was $35.12 \%$ (95\% Cl: 33.93-36.35), 15.63\% (95\% Cl: $14.74-16.59)$ and 7.83\% (95\% Cl: $7.16-$ 8.57), respectively (Fig. 5A). In addition to the nomogram, a risk classification system for prognostic 
group was also built based on each patient's total scores in the training cohort produced nomogram. The cutoff points of risk stratification were provided by X-tile software. (Yale University, New Haven, CT, USA). According to the novel classification system, all patients were divided into three groups: low-risk group $(3328 / 6015,55.3 \%$; total score < 165), intermediate-risk group $(1213 / 6015,20.2 \%$; $165 \leq$ total score < $238)$, and high-risk group $(1474 / 6015,24.5 \%$, total score $\geq 238)$. Kaplan-Meier curves were performed and demonstrated that CSS in the three prognostic groups was accurately distinguished by the risk classification system (Fig. 5B). In the total cohort, the MST of patients in the low-, intermediate-, and highrisk groups was 7.0 months (95\% $\mathrm{Cl} 6.7-7.3), 3.0$ months (95\% Cl $2.7-3.3)$, and 2.0 months $(95 \% \mathrm{Cl} 1.8-$ 2.2), respectively.

\section{Discussion}

Pancreatic cancer remains the most invariably aggressive and lethal cancer with deadly prognosis for overall survival. Improvements in the outcomes of PC have lagged behind progress made in the treatment of many other malignancies in the last decades. Despite tremendous clinical and laboratory research efforts, the 5 -year OS remain as low as $8-10 \%[2]$. PC has particularly challenging biological characteristics, such as insidious onset, biologic aggressiveness and early distant metastases, further enhancing its therapeutic resistance[15]. Most patients are diagnosed in the advanced stages of the disease because of its late presentation and rapid progression, resulting in less than $20 \%$ of patients undergoing curative surgery in the early stages [16]. Moreover, even with radical surgery, local and regional recurrence or distant metastasis eventually develops in the majority of these patients[17]. Metastasis occurs in more than half of PC patients, with the liver being the most common site [5, 8]. Liver metastasis from pancreatic cancer is a commonly fatal disease, characterized by refractory course and rapid progress. Therefore, those patients are difficult to treat and often lead to a dismal prognosis with a MST of 3-5 months[8]. This phenomenon necessitates increased understanding and advances in therapeutic approaches to significant improvements in overall survival for these entities. This study is the first attempt to establish a prognostic nomogram to predict the CSS of individual PCLM patients based on routine demographic, staging and treatment information of a large number of PCLM patients.

Age at diagnosis, primary site, histologic grade, T stage, tumor size, number of metastatic organs, and surgery, chemotherapy, and radiotherapy at the primary site were identified as independent prognostic factors for CSS. Higher age, body or tail site, larger tumor size, and higher grade were independently associated with poor prognosis in patients with PC, consistent with previous studies[18-20]. Noticeably, metastatic burden, which classified by the number of metastatic sites, shown significantly relevant to survival of PCLM patients. Preferred prognosis was seen in patients with only liver metastasis than those with extrahepatic metastasis, showing metastatic burden is a critical factor for survival. Lower T stage (T1-3), compared with primary tumors with local invasion of important blood vessels (T4), was associated with improved prognostic outcome, which had been identified in previous studies[21, 22].

The primary goal of care in MPC patients, including those with liver metastases, is to provide symptom palliation that minimizes suffering and maintains an acceptable quality of life. So far, PCLM still lacks 
effective treatment and is primarily administered by systemic chemotherapy. Similarly, local therapeutic approaches, including surgery and radiotherapy, as interventions to relieve biliary or intestinal obstruction and cancer-related pain, have brought good symptom relief and improved quality of life for patients with PCLM[23]. This proposed nomogram also indicates the prognostic implications of using different treatment methods. It is obviously observed from the nomogram results that combination cytotoxic chemotherapy remains the main treatment modality with the greatest effect on survival. Patients receiving chemotherapy have better survival benefits than those not receiving [MST: 6 vs. 23 months (HR, $0.38 ; 95 \% \mathrm{Cl}, 0.36-0.40 ; \mathrm{P}<0.001$ )] (Fig. 5C). Due to the aggressive behavior of the tumor, the chance of surgery for PCLM is very limited and therefore the chemotherapy is the preferred treatment option[24]. The two main effective regimens as first-line treatment options for well-performance metastatic patients are FOLFIRINOX (fluorouracil, leucovorin, irinotecan, and oxaliplatin) and GEM/NP (gemcitabine plus nabpaclitaxel) with MST of 11.0 and 8.5 months, respectively, compared with 6.7-7.0 months for gemcitabine alone $[11,25]$. In addition to the above two regimens, GEM combined with S-1 is recommended as a new option for first-line treatment of metastatic pancreatic cancer in the Asian population with an MST of 10.1 months [26]. Improvement in survival is generally limited to patients with adequate performance. Poorly performing patients may benefit from single-agent chemotherapy with GEM or S-1 [27, 28]. Approximately $40-50 \%$ of MPC patients will receive second- or later-line chemotherapy. In second-line therapy, favorable patients who have a good performance status in practice often receive an alternative first-line regimen that they did not initially receive. For patients with poor performance status, gemcitabine monotherapy is the preferred choice. In particular, for PCLM, transarterial chemoembolization (TACE) is a well-established modality and a promising treatment for palliative care and symptomatic relief with a MST of 19 months [29].

Surgery is significantly associated with the prognosis of PC patients, but whether surgery benefits patients with PCLM remains controversial. Generally, the presence of liver metastases is a clear indicator of non-surgical treatment. Debulking surgery is not recommended for patients with PCLM according to the latest NCCN guidelines. Historically, surgery has been used to alleviate symptoms, such as duodenal or biliary obstruction in the metastatic setting. With improvements in endoscopic techniques, the rate of duodenal and biliary stent placement has increased while the need for palliative surgical bypasses has decreased. In patients with unresectable disease and biliary obstruction, especially when anticipated survival is limited, an endoscopic biliary sent of palliation ideally will offer durable relief that maximizes life quality while minimizing morbidity and future interventions[30]. Patients can initiate or resume chemotherapy within days of endoscopic stenting, while recovery from a palliative bypass may take 3 to 6 weeks and therefore delay chemotherapy [31]. Therefore, instead of surgery, most of these patients can be relieved by a non-surgical stent procedure. However, as preoperative systemic therapy and perioperative outcomes improve, an increasing number of patients are being considered for surgical treatment. In some cases, carefully selected patients may derive a favorable survival benefit from surgical treatment. For example, conversion surgery following a good response to neoadjuvant chemotherapy in synchronous metastatic disease or metastasectomy for metachronous liver oligometastases with a high potential for a R0 resection is possible and feasible. The MST was from 5.9 to 14.5 months and the 5- 
year survival rates were from $0 \%$ and $7 \%$ in reported retrospective studies of surgical resection for PCLM[32-35]. Some studies have revealed that patients with PCLM benefit from resection and have longer survival compared to patients receiving chemotherapy or other palliative treatments, while other studies have failed to find significant differences in survival. In our study, these patients who underwent the surgery to primary site had a better prognosis with MST of 10 months vs. 4 months (HR, $0.47 ; 95 \% \mathrm{Cl}$, $0.40-0.56 ; \mathrm{P}<0.001$ )] (Fig. 5D). However, there is no agreed consensus concerning the role of surgical management for patients with PCLM, and the long-term prognosis of conversion surgery and metastasectomy for PCLM requires to be sufficiently investigated.

In addition to surgery, radiation (RT), as another local treatment, also is of great importance in the management of PCLM for local control and symptom palliation. Patients with metastatic disease are usually not candidates for RT; however, patients with metastatic disease requiring local palliation for symptoms, like obstruction, pain refractory to analgesic therapy, or bleeding, may be treated with palliative RT [36]. In the present study, patients treated with radiation demonstrate a modest survival benefit with MST of 6 months vs. 4 months (HR, 0.83; 95\% Cl, 0.73-0.94; P<0.001)] (Fig. 5E). In selected patients with metachronous liver oligometastases, stereotactic body radiotherapy (SBRT) has been reported as an effective treatment option and has been proven to have a positive effect on patients' quality of life, local control and potentially survival in the cases of other tumors[37-40]. Reported local control rate at 1 year was $71 \%$, corresponding to a MST of 17.6 months in isolated liver metastases from colorectal and breast primaries[38]. Goodman et al[41] reported the experience of 19 patients with metastatic liver cancer (including 3 patients with PCLM) treated with SBRT, with a prescribed radiation dose of 18-30Gy. All patients tolerated well without severe adverse effects, with a MST of 28.6 months and a 2-year overall survival rate of $50.4 \%$. A significant reduction in pain 4 to 6 weeks was reported after 33Gy SBRT (6.6Gy $\times 5$ fractions) in combination with GEM in patients with PLCM[42]. For patients with synchronous metastatic disease on an initial presentation, intensive systemic therapy stays the standard of care. Immunotherapy has shown clinical benefit with a favorable toxicity profile and are approved in multiple tumor types. An increase in peripheral antitumor immunity following radiation has been revealed in several studies[43-45]. Multimodality care of combined radiation with immune checkpoint inhibitors (ICls) may offer better local tumor regression and systemic control in the metastatic disease. Xie et al[46] conducted a phase I study to evaluate the safety of ICls with SBRT in patients with MPC. Results indicated the combination of ICl and SBRT demonstrated a modest treatment benefit with an acceptable safety profile in these patients.

To significantly improve the therapeutic efficiency of tumors, combination therapies have been widely used in the standard of care. Combination therapy showed more desirable survival periods than the single therapy (Fig. 6A-B). The longest MST can reach 17.0 months with systemic therapy combined the surgery and chemoradiotherapy. The traditional standard of care merely manage to extend the survival of the patients with PCLM, which demands various alternative treatment modalities being explored. Currently, in the precision oncologic and immune era, immunotherapy and molecularly targeted therapy outcomes promise to improve lifespan for the metastatic disease. Immunotherapy, represented by immune checkpoint inhibitors with PD-1/PD-L1 monoclonal antibody, has demonstrated promising 
benefits might enable long-term survival in cases of high microsatellite instability (MSI-H) or deficiency mismatch repair (dMMR)[47]. Aspects of the benefit of poly (ADP-ribose) polymerase (PARP) inhibitior as maintenance therapy for patients with germline BRCA-mutated metastatic disease and no disease progression after 4-6 months of first-line platinum-based therapy represent a signal of progress in molecularly targeted therapy[48].

These breakthroughs have encouraged the pursuit of molecularly targeted therapeutic options to investigate the benefits of personalized strategies for the treatment of PC. Kinases have recently emerged as attractive therapeutic candidates because they mediate key cellular pathways by phosphorylating signaling molecules associated with gene expression, membrane trafficking, cell growth, metabolic pathways, differentiation, and cell death. Erlotinib, an epidermal growth factor receptor (EGFR) tyrosine kinase inhibitor (TKI), is being explored as a first-line option for metastatic treatment. Results suggested that GEM in combination with erlotinib prolonged overall survival with MST of 6.24 months vs. 5.91 months $(P=0.023)$, respectively[49]. Other kinases, such as masitinib, ruxolitinib, similarly exhibit evidence of efficacy[50,51]. In the near future, novel agents specifically targeting pathological signaling pathways and genetic alterations specific to PC patients should be combined with traditional standard of care treatments and novel approaches (ie, immunotherapy and targeting the extracellular tumour microenvironment or metabolism) to achieve substantial survival benefits while reducing side effects. SSGJ-705 is a bispecific antibody simultaneously targeting both PD1 and HER2 in an attempt to combine HER2-targeted therapy with immune checkpoint blockade for treating HER2-positive solid tumors[52]. A phase I, multicenter, open-label, first-in-human clinical trial to evaluate the safety, tolerability, pharmacokinetics and potential anti-tumor effects of SSGJ-705 in patients with advanced or metastatic HER2-expressing solid tumors has been approved by FDA. In conclusion, advances in systemic therapy and multidisciplinary standards of care promise to improve both lifespan and health span in this dismal disease.

The present study has several limitations. First, this study is a retrospective analysis with the inherent bias of retrospective data collection. Second, the prediction model was based on data from the SEER database, which makes its application in Asian and Chinese populations immature due to ethnic differences. Third, due to the limitations of the SEER database, details of chemotherapy regimens and radiotherapy doses are not available, which will greatly affect the applicability of the study in the real world. Finally, although the nomogram has achieved acceptable predictive and risk stratification efficacy in training and validation cohorts, further study needs to be warranted.

\section{Conclusion}

We developed and validated a nomogram and corresponding risk classification system for predicting the CSS for PCLM patients using clinicopathological and treatment-related factors. Moreover, our study reveals the diversity in treatment practices and prognostic outcomes in PCLM in a real-world setting in current era. 


\section{Abbreviations}

pancreatic cancer liver metastasis $\triangle P C L M)$, pancreatic cancer (PC); cancer-specific survival (CSS); Surveillance, Epidemiology, and End Results (SEER); concordance index (C-index); decision curve analyses (DCAs); receiver operating characteristic (ROC); median survival time (MST); $95 \%$ confidence interval [Cl]; transarterial chemoembolization (TACE); radiation (RT); stereotactic body radiotherapy (SBRT); immune checkpoint inhibitors (ICls); high microsatellite instability (MSI-H) deficiency mismatch repair (dMMR); epidermal growth factor receptor (EGFR)

\section{Declarations}

Authors' contributions: Jing Wang, and Biyang Cao designed the research. Biyang Cao and Chenchen Wu performed the research and analyzed results. Biyang Cao wrote the paper. Jing Wang, Chenchen Wu and Letian Zhang edited the manuscript and provided critical comments. All authors read and approved the final manuscript.

Funding: This work was supported by National Key Research and Development Program granted 2017YFC0112100

Availability of data and materials: The datasets used or analysed during the current study are available from the corresponding author on reasonable request.

Ethics statement: Our research is based on the National Cancer Institute's SEER program. For this study, we signed the SEER research data agreement to access SEER information, using reference number 21819-Nov2019. Data were obtained following the approved guidelines. The Office for Human Research Protection considered this research to be on nonhuman subjects because the subjects were patients who had been researched by the United States Department of Health and Human Services and were publicly accessible and de-identified. Thus, no institutional review board approval was required.

\section{Conflict of Interest: None}

Consent for publication: Written informed consent for publication was obtained from all participants.

Acknowledgments: This work was supported by a research grant from National Key Research and Development Program. The authors sincerely appreciate the efforts of the Surveillance, Epidemiology, and End Results (SEER) Program tumor registries in establishment of the SEER database.

\section{References}

1. Sung H, Ferlay J, Siegel RL, Laversanne M, Soerjomataram I, Jemal A, Bray F: Global cancer statistics 2020: GLOBOCAN estimates of incidence and mortality worldwide for 36 cancers in 185 countries. CA Cancer J Clin 2021. 
2. Grossberg AJ, Chu LC, Deig CR, Fishman EK, Hwang WL, Maitra A, Marks DL, Mehta A, Nabavizadeh $\mathrm{N}$, Simeone DM et al: Multidisciplinary standards of care and recent progress in pancreatic ductal adenocarcinoma. CA Cancer J Clin 2020, 70(5):375-403.

3. Abrams RA, Lowy AM, O'Reilly EM, Wolff RA, Picozzi VJ, Pisters PWT: Combined modality treatment of resectable and borderline resectable pancreas cancer: expert consensus statement. Ann Surg Oncol 2009, 16(7):1751-1756.

4. Shi H, Li J, Fu D: Process of hepatic metastasis from pancreatic cancer: biology with clinical significance. J Cancer Res Clin Oncol 2016, 142(6):1137-1161.

5. Nieto J, Grossbard ML, Kozuch P: Metastatic pancreatic cancer 2008: is the glass less empty? Oncologist 2008, 13(5):562-576.

6. Heinemann V, Haas M, Boeck S: Systemic treatment of advanced pancreatic cancer. Cancer Treat Rev 2012, 38(7):843-853.

7. Conroy T, Hammel P, Hebbar M, Ben Abdelghani M, Wei AC, Raoul J-L, Choné L, Francois E, Artru P, Biagi JJ et al: FOLFIRINOX or Gemcitabine as Adjuvant Therapy for Pancreatic Cancer. N Engl J Med 2018, 379(25):2395-2406.

8. McGuigan A, Kelly P, Turkington RC, Jones C, Coleman HG, McCain RS: Pancreatic cancer: A review of clinical diagnosis, epidemiology, treatment and outcomes. World J Gastroentero/ 2018, 24(43):4846-4861.

9. Houg DS, Bijlsma MF: The hepatic pre-metastatic niche in pancreatic ductal adenocarcinoma. $\mathrm{Mol}$ Cancer 2018, 17(1):95.

10. De Dosso S, Siebenhüner AR, Winder T, Meisel A, Fritsch R, Astaras C, Szturz P, Borner M: Treatment landscape of metastatic pancreatic cancer. Cancer Treat Rev 2021, 96:102180.

11. Sohal DPS, Kennedy EB, Cinar P, Conroy T, Copur MS, Crane CH, Garrido-Laguna I, Lau MW, Johnson T, Krishnamurthi S et al: Metastatic Pancreatic Cancer: ASCO Guideline Update. Journal of clinical oncology : official journal of the American Society of Clinical Oncology 2020:JC02001364.

12. Segelov E, Lordick F, Goldstein D, Chantrill LA, Croagh D, Lawrence B, Arnold D, Chau I, Obermannova $\mathrm{R}$, Price TJ: Current challenges in optimizing systemic therapy for patients with pancreatic cancer: expert perspectives from the Australasian Gastrointestinal Trials Group (AGITG) with invited international faculty. Expert Rev Anticancer Ther 2017, 17(10):951-964.

13. Balachandran VP, Gonen M, Smith JJ, DeMatteo RP: Nomograms in oncology: more than meets the eye. The Lancet Oncology 2015, 16(4):e173-e180.

14. He C, Zhong L, Zhang Y, Cai Z, Lin X: Development and validation of a nomogram to predict liver metastasis in patients with pancreatic ductal adenocarcinoma: a large cohort study. Cancer management and research 2019, 11:3981-3991.

15. Oberstein PE, Olive KP: Pancreatic cancer: why is it so hard to treat? Therap Adv Gastroentero/ 2013, 6(4):321-337.

16. Mizrahi JD, Surana R, Valle JW, Shroff RT: Pancreatic cancer. The Lancet 2020, 395(10242):20082020. 
17. Griffin JF, Smalley SR, Jewell W, Paradelo JC, Reymond RD, Hassanein RE, Evans RG: Patterns of failure after curative resection of pancreatic carcinoma. Cancer 1990, 66(1):56-61.

18. Li G, Chen J-Z, Chen S, Lin S-Z, Pan W, Meng Z-W, Cai X-R, Chen Y-L: Development and validation of novel nomograms for predicting the survival of patients after surgical resection of pancreatic ductal adenocarcinoma. Cancer medicine 2020, 9(10):3353-3370.

19. He C, Sun S, Zhang Y, Lin X, Li S: Score for the Overall Survival Probability of Patients With Pancreatic Adenocarcinoma of the Body and Tail After Surgery: A Novel Nomogram-Based Risk Assessment. Frontiers in oncology 2020, 10:590.

20. Zou Y, Han H, Ruan S, Jian Z, Jin L, Zhang Y, Chen Z, Yin Z, Ma Z, Jin H et al: Development of a Nomogram to Predict Disease-Specific Survival for Patients After Resection of a Non-Metastatic Adenocarcinoma of the Pancreatic Body and Tail. Frontiers in oncology 2020, 10:526602.

21. Zhu L, Sun X, Bai W: Nomograms for Predicting Cancer-Specific and Overall Survival Among Patients With Endometrial Carcinoma: A SEER Based Study. Front Onco/ 2020, 10:269.

22. Su BB, Bai DS, Yu JQ, Zhang C, Jin SJ, Zhou BH, Jiang GQ: Can Patients with Pancreatic Cancer and Liver Metastases Obtain Survival Benefit from Surgery? A Population-Based Study. J Cancer 2021, 12(2):539-552.

23. Jin T, Dai C, Xu F: Surgical and local treatment of hepatic metastasis in pancreatic ductal adenocarcinoma: recent advances and future prospects. Ther Adv Med Oncol 2020, 12:1758835920933034.

24. Tempero MA, Malafa MP, Al-Hawary M, Asbun H, Bain A, Behrman SW, Benson AB, Binder E, Cardin DB, Cha $C$ et al: Pancreatic Adenocarcinoma, Version 2.2017, NCCN Clinical Practice Guidelines in Oncology. J Natl Compr Canc Netw 2017, 15(8):1028-1061.

25. Gourgou-Bourgade S, Bascoul-Mollevi C, Desseigne F, Ychou M, Bouché O, Guimbaud R, Bécouarn Y, Adenis A, Raoul J-L, Boige $V$ et al: Impact of FOLFIRINOX compared with gemcitabine on quality of life in patients with metastatic pancreatic cancer: results from the PRODIGE 4/ACCORD 11 randomized trial. Journal of clinical oncology : official journal of the American Society of Clinical Oncology 2013, 31(1):23-29.

26. Ueno H, loka T, Ikeda M, Ohkawa S, Yanagimoto H, Boku N, Fukutomi A, Sugimori K, Baba H, Yamao $\mathrm{K}$ et al: Randomized phase III study of gemcitabine plus S-1, S-1 alone, or gemcitabine alone in patients with locally advanced and metastatic pancreatic cancer in Japan and Taiwan: GEST study. Journal of clinical oncology : official journal of the American Society of Clinical Oncology 2013, 31(13):1640-1648.

27. Li Y, Sun J, Jiang Z, Zhang L, Liu G: Gemcitabine and S-1 combination chemotherapy versus gemcitabine alone for locally advanced and metastatic pancreatic cancer: a meta-analysis of randomized controlled trials in Asia. J Chemother 2015, 27(4):227-234.

28. Burris HA, Moore MJ, Andersen J, Green MR, Rothenberg ML, Modiano MR, Cripps MC, Portenoy RK, Storniolo AM, Tarassoff $P$ et al: Improvements in survival and clinical benefit with gemcitabine as 
first-line therapy for patients with advanced pancreas cancer: a randomized trial. Journal of clinical oncology : official journal of the American Society of Clinical Oncology 1997, 15(6):2403-2413.

29. VogI TJ, Mohamed SA, Albrecht MH, Gruber-Roh T, Lin H, Nour Eldin NEA, Bednarova I, Naguib NN, Panahi B: Transarterial chemoembolization in pancreatic adenocarcinoma with liver metastases: MR-based tumor response evaluation, apparent diffusion coefficient (ADC) patterns, and survival rates. Pancreatology : official journal of the International Association of Pancreatology (IAP) [et al] 2018, 18(1):94-99.

30. Stark A, Hines OJ: Endoscopic and operative palliation strategies for pancreatic ductal adenocarcinoma. Semin Oncol 2015, 42(1):163-176.

31. Artifon ELA, Sakai P, Cunha JEM, Dupont A, Filho FM, Hondo FY, Ishioka S, Raju GS: Surgery or endoscopy for palliation of biliary obstruction due to metastatic pancreatic cancer. $A m \mathrm{~J}$ Gastroenterol 2006, 101(9):2031-2037.

32. Gleisner AL, Assumpcao L, Cameron JL, Wolfgang CL, Choti MA, Herman JM, Schulick RD, Pawlik TM: Is resection of periampullary or pancreatic adenocarcinoma with synchronous hepatic metastasis justified? Cancer 2007, 110(11):2484-2492.

33. Shrikhande SV, Kleeff J, Reiser C, Weitz J, Hinz U, Esposito I, Schmidt J, Friess H, Büchler MW: Pancreatic resection for M1 pancreatic ductal adenocarcinoma. Ann Surg Oncol 2007, 14(1):118127.

34. Seelig SK, Burkert B, Chromik AM, Tannapfel A, Uhl W, Seelig MH: Pancreatic resections for advanced M1-pancreatic carcinoma: the value of synchronous metastasectomy. HPB Surg 2010, 2010:579672.

35. Yamamoto M, Yoshida M, Furuse J, Sano K, Ohtsuka M, Yamashita S, Beppu T, Iwashita Y, Wada K, Nakajima TE et al: Clinical practice guidelines for the management of liver metastases from extrahepatic primary cancers 2021. J Hepatobiliary Pancreat Sci 2021, 28(1):1-25.

36. National Comprehensive Cancer Network (NCCN) Clinical Practice Guidelines in Oncology. Pancreatic Adenocarcinoma, Version 2.2021.

[https://www.nccn.org/professionals/physician_gls/pdf/pancreatic.pdf.]

37. Mutsaers A, Greenspoon J, Walker-Dilks C, Swaminath A: Systematic review of patient reported quality of life following stereotactic ablative radiotherapy for primary and metastatic liver cancer. Radiat Oncol 2017, 12(1):110.

38. Lee MT, Kim JJ, Dinniwell R, Brierley J, Lockwood G, Wong R, Cummings B, Ringash J, Tse RV, Knox $\mathrm{JJ}$ et al: Phase I study of individualized stereotactic body radiotherapy of liver metastases. Journal of clinical oncology : official journal of the American Society of Clinical Oncology 2009, 27(10):15851591.

39. Scorsetti M, Clerici E, Comito T: Stereotactic body radiation therapy for liver metastases. J Gastrointest Oncol 2014, 5(3):190-197.

40. Petrelli F, Comito T, Barni S, Pancera G, Scorsetti M, Ghidini A: Stereotactic body radiotherapy for colorectal cancer liver metastases: A systematic review. Radiother Oncol 2018, 129(3):427-434. 
41. Robin TP, Raben D, Schefter TE: A Contemporary Update on the Role of Stereotactic Body Radiation Therapy (SBRT) for Liver Metastases in the Evolving Landscape of Oligometastatic Disease Management. Semin Radiat Oncol 2018, 28(4):288-294.

42. Wild AT, Hiniker SM, Chang DT, Tran PT, Khashab MA, Limaye MR, Laheru DA, Le DT, Kumar R, Pai JS et al: Re-irradiation with stereotactic body radiation therapy as a novel treatment option for isolated local recurrence of pancreatic cancer after multimodality therapy: experience from two institutions. $J$ Gastrointest Oncol 2013, 4(4):343-351.

43. Blanquicett C, Saif MW, Buchsbaum DJ, Eloubeidi M, Vickers SM, Chhieng DC, Carpenter MD, Sellers JC, Russo S, Diasio RB et al: Antitumor efficacy of capecitabine and celecoxib in irradiated and leadshielded, contralateral human BxPC-3 pancreatic cancer xenografts: clinical implications of abscopal effects. Clin Cancer Res 2005, 11(24 Pt 1):8773-8781.

44. Demaria S, Ng B, Devitt ML, Babb JS, Kawashima N, Liebes L, Formenti SC: Ionizing radiation inhibition of distant untreated tumors (abscopal effect) is immune mediated. International journal of radiation oncology, biology, physics 2004, 58(3):862-870.

45. Lee Y, Auh SL, Wang Y, Burnette B, Wang Y, Meng Y, Beckett M, Sharma R, Chin R, Tu T et al: Therapeutic effects of ablative radiation on local tumor require $C D 8+T$ cells: changing strategies for cancer treatment. Blood 2009, 114(3):589-595.

46. Xie C, Duffy AG, Brar G, Fioravanti S, Mabry-Hrones D, Walker M, Bonilla CM, Wood BJ, Citrin DE, Gil Ramirez EM et al: Immune Checkpoint Blockade in Combination with Stereotactic Body Radiotherapy in Patients with Metastatic Pancreatic Ductal Adenocarcinoma. Clin Cancer Res 2020, 26(10):23182326.

47. Christenson ES, Jaffee E, Azad NS: Current and emerging therapies for patients with advanced pancreatic ductal adenocarcinoma: a bright future. Lancet Oncol 2020, 21(3):e135-e145.

48. Golan T, Hammel P, Reni M, Van Cutsem E, Macarulla T, Hall MJ, Park J-O, Hochhauser D, Arnold D, Oh D-Y et al: Maintenance Olaparib for Germline -Mutated Metastatic Pancreatic Cancer. N Eng/ J Med 2019, 381(4):317-327.

49. Moore MJ, Goldstein D, Hamm J, Figer A, Hecht JR, Gallinger S, Au HJ, Murawa P, Walde D, Wolff RA et al: Erlotinib plus gemcitabine compared with gemcitabine alone in patients with advanced pancreatic cancer: a phase III trial of the National Cancer Institute of Canada Clinical Trials Group. Journal of clinical oncology : official journal of the American Society of Clinical Oncology 2007, 25(15):1960-1966.

50. Deplanque G, Demarchi M, Hebbar M, Flynn P, Melichar B, Atkins J, Nowara E, Moyé L, Piquemal D, Ritter $\mathrm{D}$ et al: A randomized, placebo-controlled phase III trial of masitinib plus gemcitabine in the treatment of advanced pancreatic cancer. Ann Oncol 2015, 26(6):1194-1200.

51. Ruxolitinib Benefits Some with Pancreatic Cancer. Cancer Discov 2015, 5(12):1231.

52. Gu C-L, Zhu H-X, Deng L, Meng X-Q, Li K, Xu W, Zhao L, Liu Y-Q, Zhu Z-P, Huang H-M: Bispecific antibody simultaneously targeting PD1 and HER2 inhibits tumor growth via direct tumor cell killing in combination with PD1/PDL1 blockade and HER2 inhibition. Acta Pharmacol Sin 2021. 


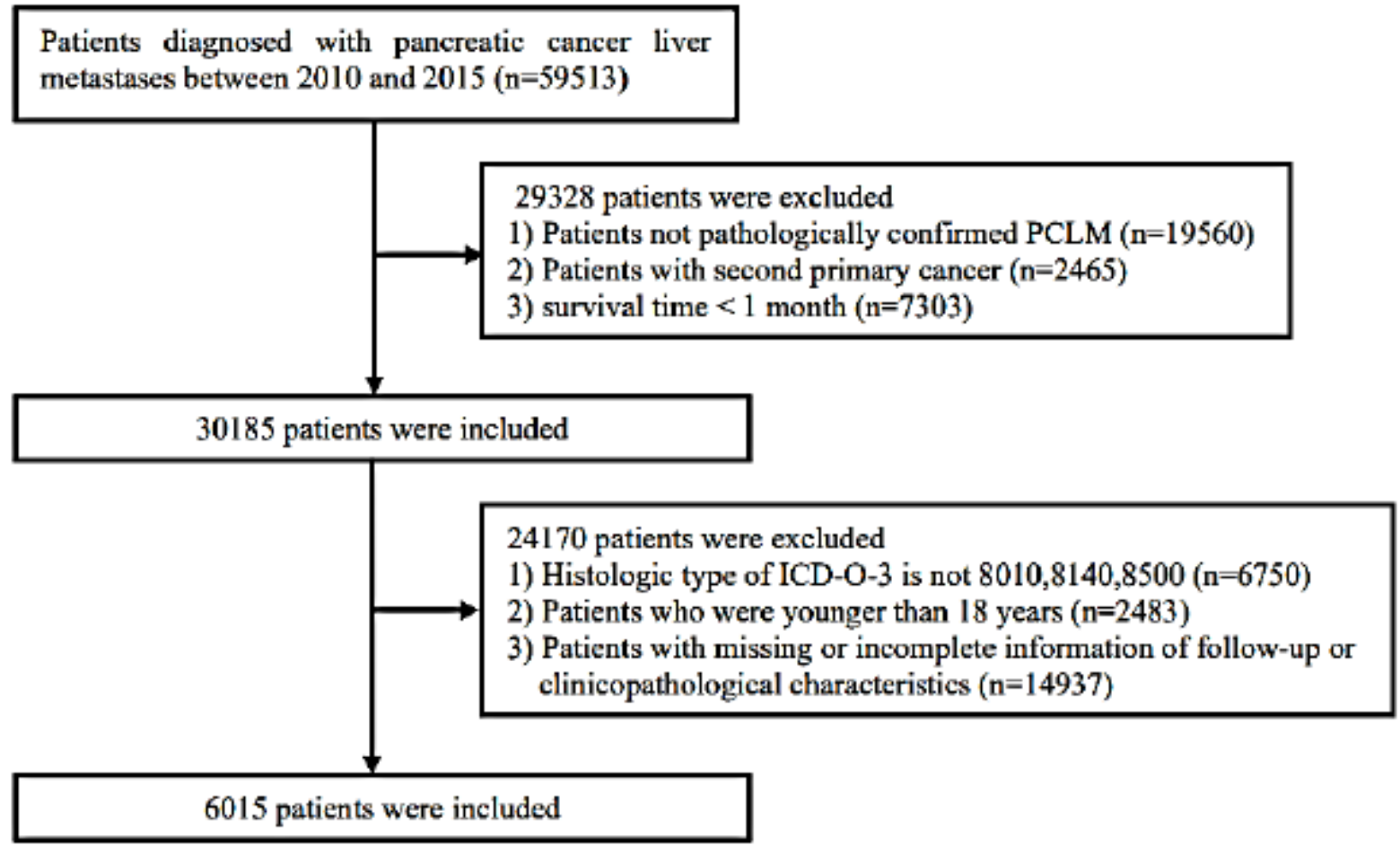

\section{Figure 1}

Flow diagram of the data selection process. 


\begin{tabular}{|c|c|c|c|c|}
\hline Characteristics & $\mathrm{N}(\%)$ & $\mathrm{HR}(95 \% \mathrm{Cl})$ & & $\mathrm{P}$ value \\
\hline Age (years) & & & $T$ & \\
\hline$<60$ & $1824(30.3)$ & & 1 & \\
\hline $60-80$ & $3681(61.2)$ & $1.22(1.15,1.30)$ & $1 \%$ & $<0.001$ \\
\hline$>80$ & $510(8.48)$ & $1.61(1.45,1.79)$ & I & $<0.001$ \\
\hline Primary site & & & 1 & \\
\hline Head & $2306(38.3)$ & & 1 & \\
\hline Body & $1093(18.2)$ & $0.99(0.91,1.07)$ & w & 0.748 \\
\hline Tail & $1474(24.5)$ & $1.12(1.05,1.21)$ & int & 0.001 \\
\hline Other & $1142(19.0)$ & $1.03(0.96,1.12)$ & br & 0.379 \\
\hline Histologic grade & & & i & \\
\hline Grade I-II & $655(10.9)$ & & 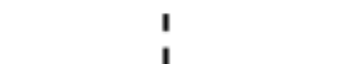 & \\
\hline Grade III-IV & $786(13.1)$ & $1.38(1.24,1.54)$ & $1 \mapsto$ & $<0.001$ \\
\hline Unspecific & $4574(76.0)$ & $1.24(1.13,1.35)$ & $1 \mapsto$ & $<0.001$ \\
\hline T stage & & & i & \\
\hline $\mathrm{T} 1$ & $326(5.4)$ & & 1 & \\
\hline $\mathrm{T} 2$ & $2362(39.3)$ & $1.10(0.97-1.23)$ & ror & 0.131 \\
\hline T3 & $2474(41.1)$ & $1.13(1.01-1.31)$ & L $\rightarrow$ & 0.041 \\
\hline $\mathrm{T} 4$ & $853(14.2)$ & $0.99(0.86-1.14)$ & $\rightarrow-1$ & 0.868 \\
\hline Tumor size (cm) & & & 1 & \\
\hline$\leq 4.4$ & $3499(58.2)$ & & i & \\
\hline$>4.4$ & $2516(41.8)$ & $1.17(1.08,1.28)$ & $I n a-1$ & $<0.001$ \\
\hline Metastatic burden & & & i & \\
\hline 1 & $4856(80.7)$ & & 1 & \\
\hline 2 & $1022(17.0)$ & $1.47(1.03,2.11)$ & 邽 & 0.035 \\
\hline 3 & $132(2.19)$ & $1.94(0.94,3.97)$ & $\stackrel{1}{1}$ & 0.071 \\
\hline$\geq 4$ & $5(0.08)$ & & i & \\
\hline Surgery & & & i & \\
\hline No & $5830(96.9)$ & & i & \\
\hline Yes & $185(3.08)$ & $0.46(0.39,0.54)$ & H & $<0.001$ \\
\hline Radiation & & & i & \\
\hline No & $5748(95.6)$ & & i & \\
\hline Yes & $267(4.44)$ & $0.87(0.76,0.98)$ & $\mapsto-4$ & 0.028 \\
\hline Chemotherapy & & & i & \\
\hline No & $1944(32.3)$ & & i & \\
\hline \multirow[t]{2}{*}{ Yes } & $4071(67.7)$ & $0.38(0.36,0.40)$ & $\bullet$ & $<0.001$ \\
\hline & & & 0.5 & \\
\hline
\end{tabular}

Figure 2

Forest plot analysis of prognostic factors associated with CSS 
Points

Age at diagnosis

Primary site

Histologic grade

T stage

Tumor size $(\mathrm{cm})$

Metastastic burden

Surgery to primary site

Radiation

Chemotherapy

Total Points

Risk classification

6-Month CSS

12-Month CSS

18-Month CSS

Median CSS
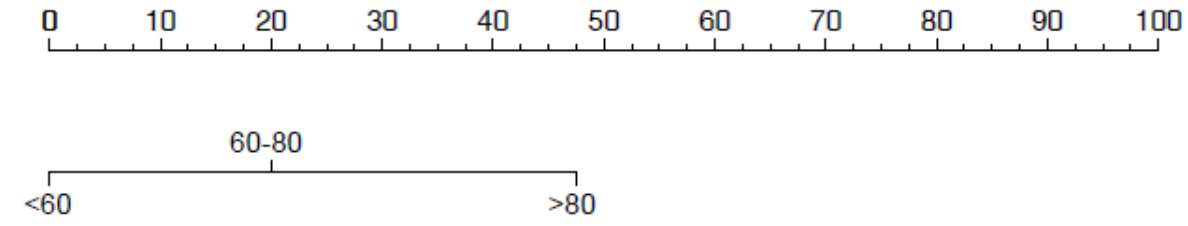

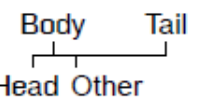

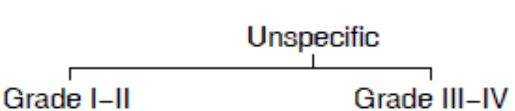

Grade I-II Grade III-IV
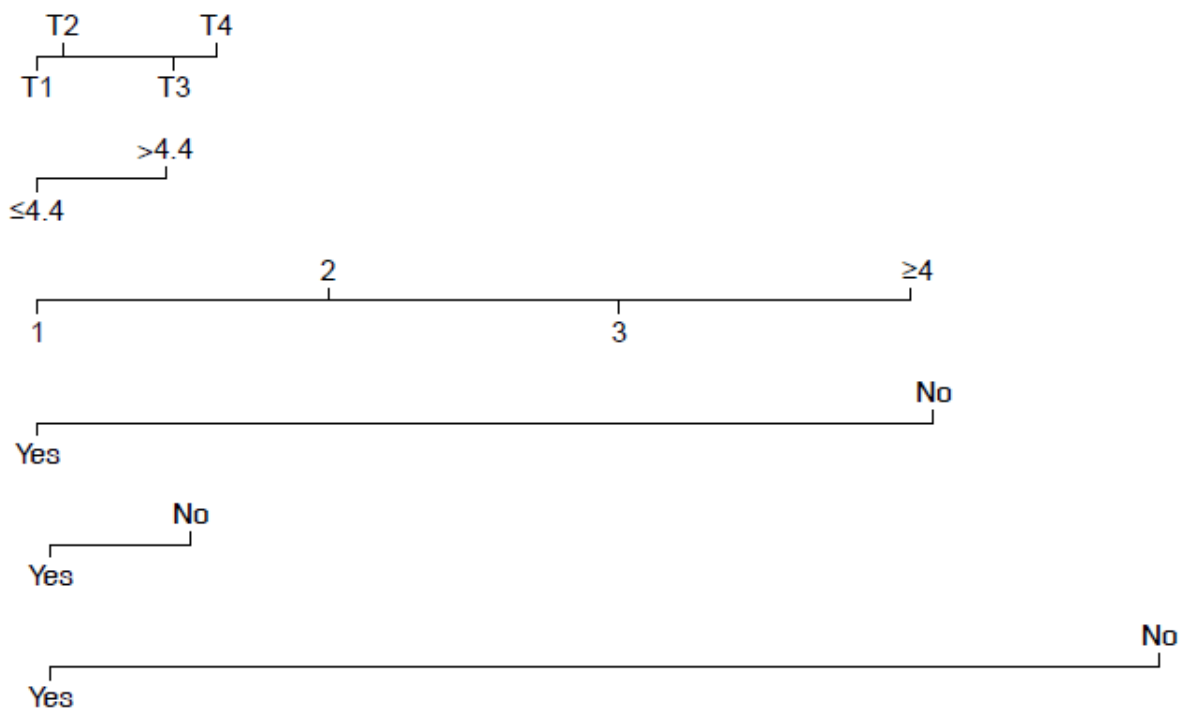

\begin{tabular}{lllllllll}
\hline & 1 & 1 & 1 & 1 & 1 & 1 & 1 & 1 \\
0 & 50 & 100 & 150 & 200 & 250 & 300 & 350 & 400
\end{tabular}

\begin{tabular}{|l|l|l}
\hline Low-Risk & Intermediate-Risk & High-Risk \\
\hline
\end{tabular}

\begin{tabular}{lllllllll}
\hline 0.85 & 0.80 & 0.70 & 0.6 & 0.5 & 0.4 & 0.3 & 0.2 & 0.1
\end{tabular}

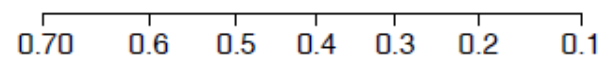

$\begin{array}{llllll}0.6 & 0.5 & 0.4 & 0.3 & 0.2 & 0.1\end{array}$

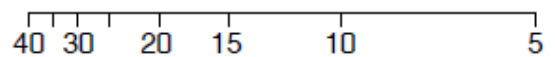

\section{Figure 3}

Nomogram predicting the CSS and corresponding risk classification system for patients with initially diagnosed PCLM. 
A

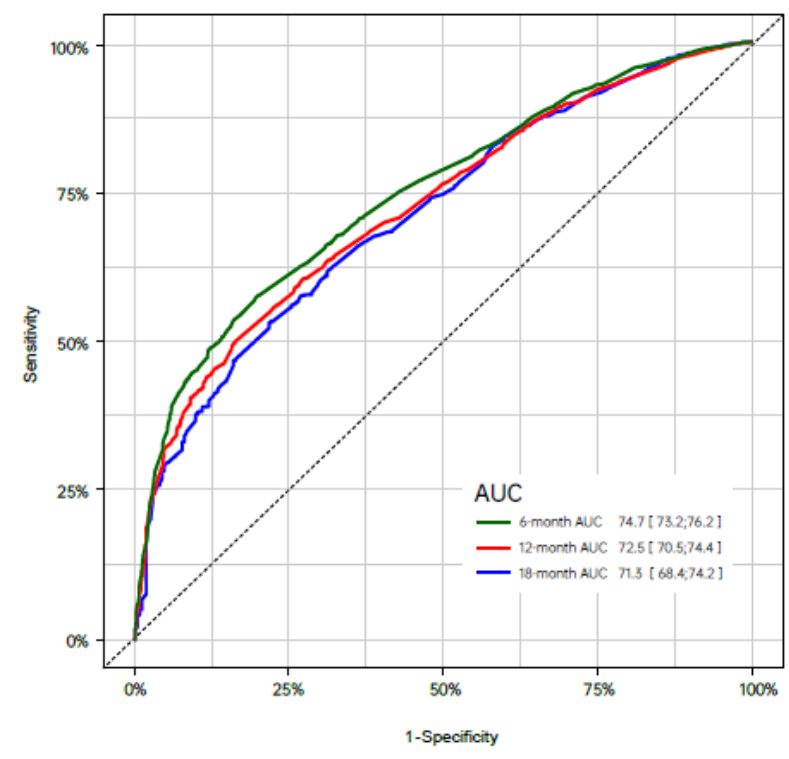

C

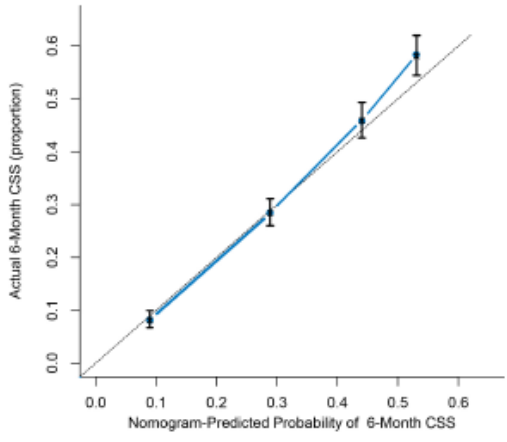

$\mathrm{F}$
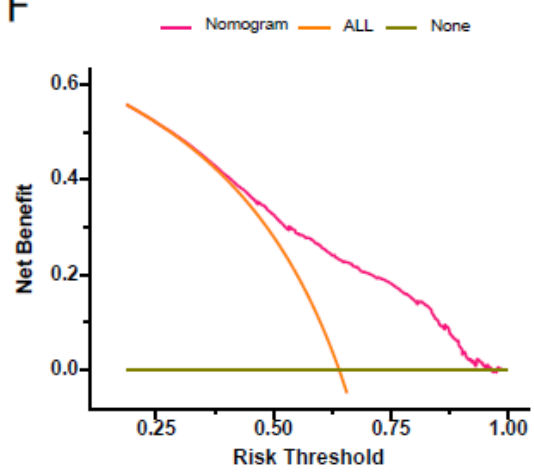

B

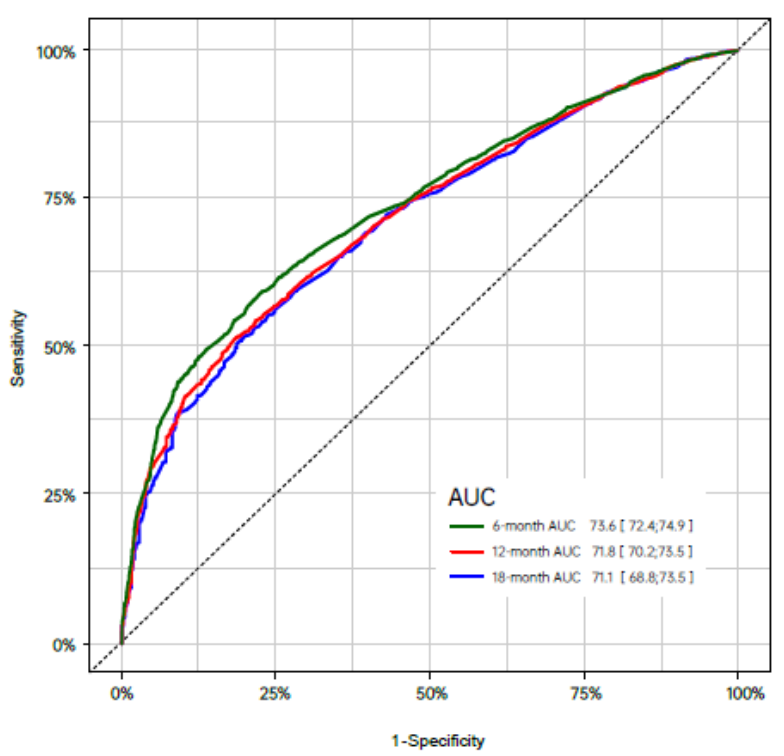

$\mathrm{E}$

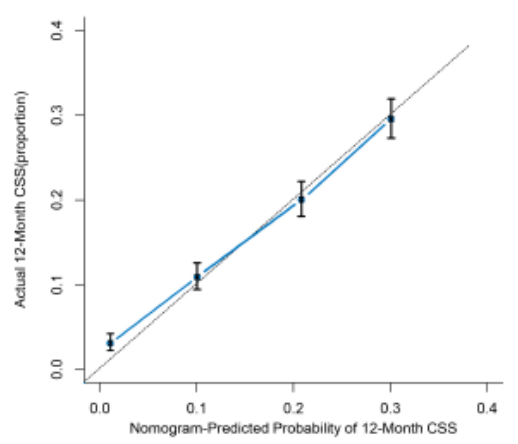

G _ Nomogram - AlL - None

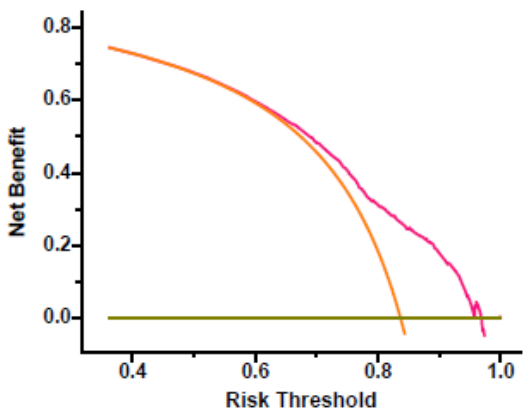

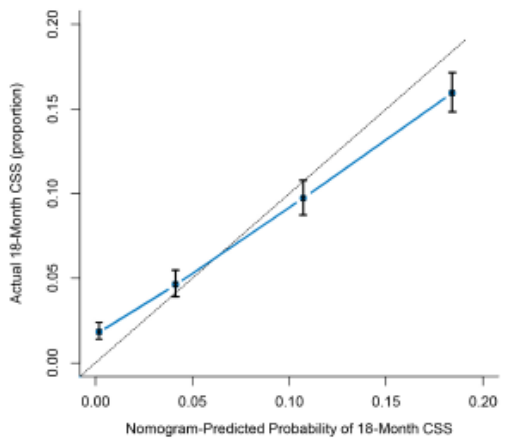

$\mathrm{H} \quad$ - Nomogram - all - None

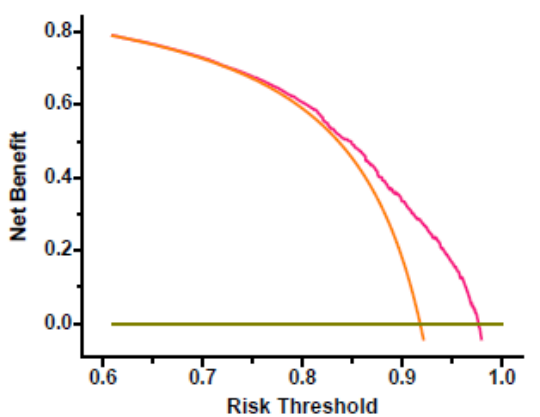

\section{Figure 4}

A-B: ROC curves of the nomogram for 6-, 12-, and 18-month CSS prediction in the training and validation cohort. C-E: Calibration curves showing the probability of 6-, 12-, and 18-month CSS between the nomogram prediction and the actual observation. F-H: Decision curves of the nomogram predicting 6-, $12-$, and 18-month CSS. 
A Kaplan-Meier Curve for Css

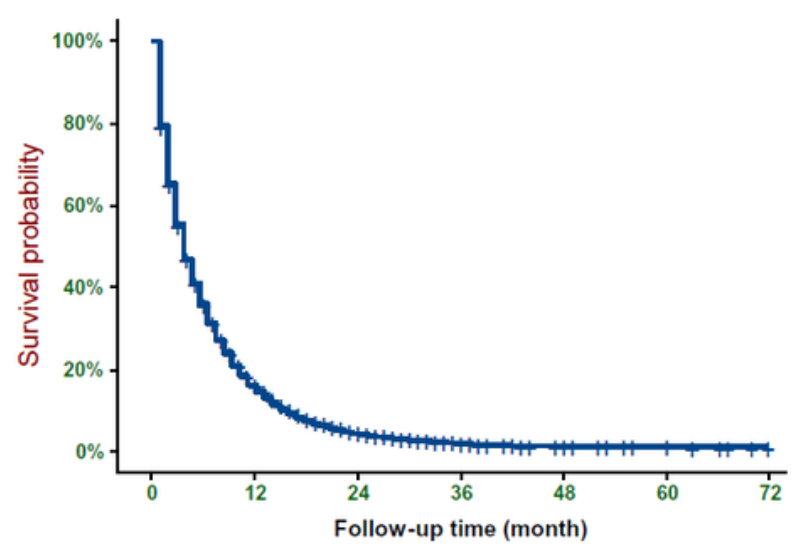

C Kaplan-Meier Curve for css

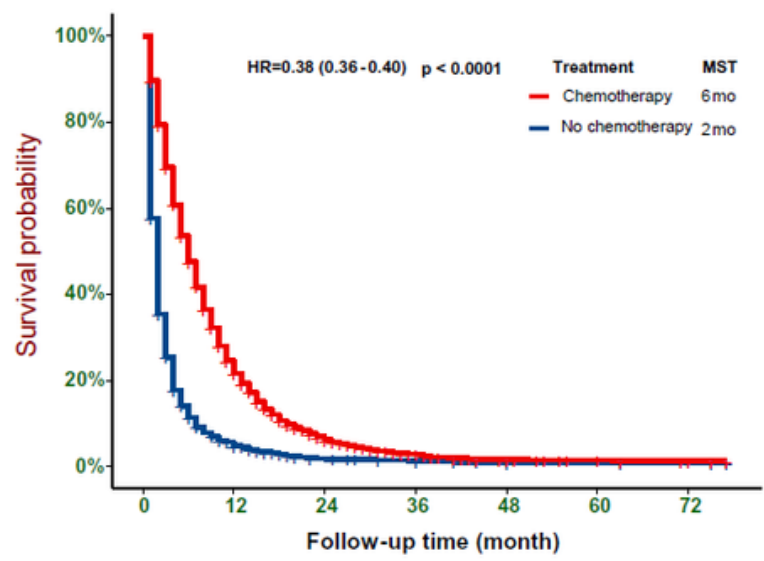

E Kaplan-Meier Curve for CSS

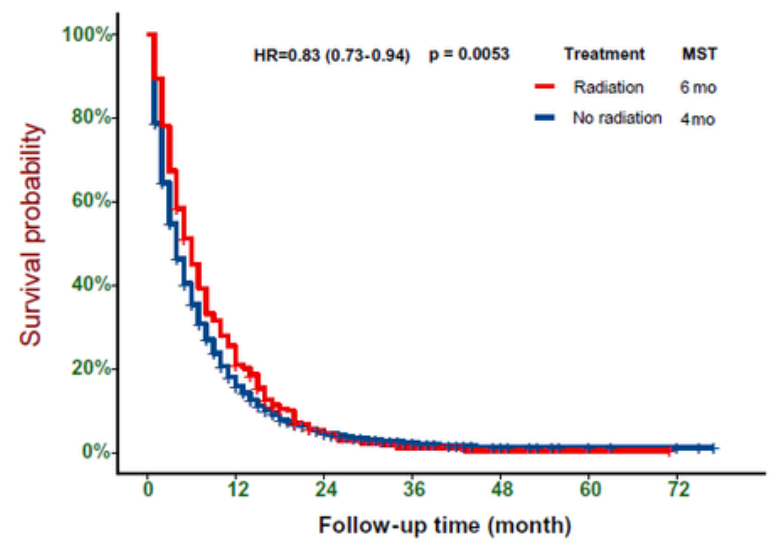

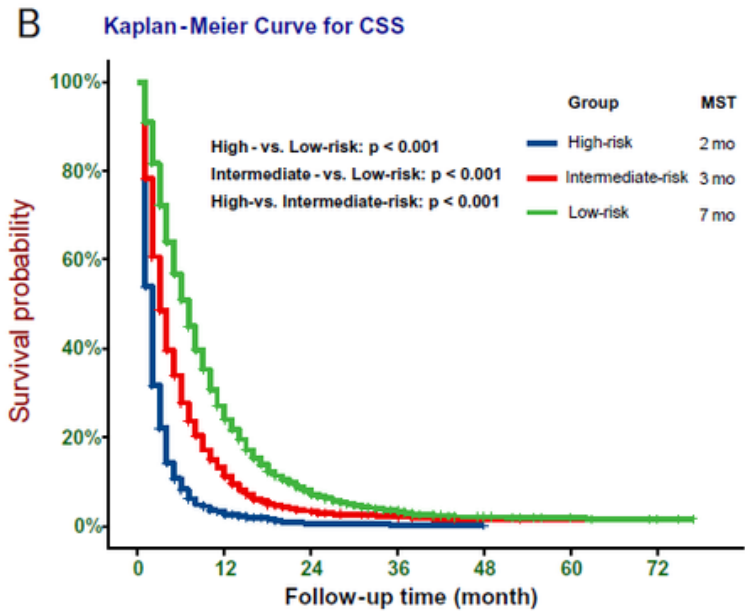

D Kaplan-Meier Curve for css

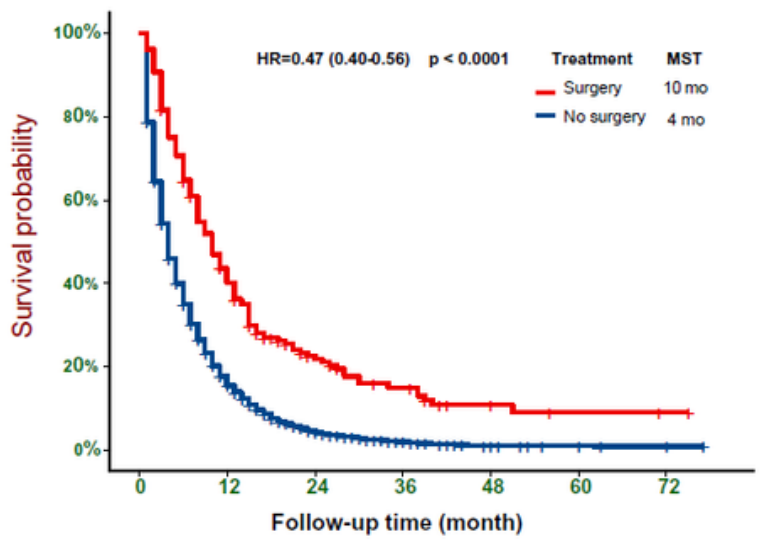

\section{Figure 5}

A: Kaplan-Meier curves of overall CSS for PCLM patients in the study. B: Kaplan-Meier curves of CSS for patients according to the risk groups of the nomogram in all cohort of PCLM patients. C-E: Kaplan-Meier curves of CSS for PCLM patients with or without chemotherapy (C), surgery (D), radiotherapy (E). 
A Kaplan-Meier Curve for css

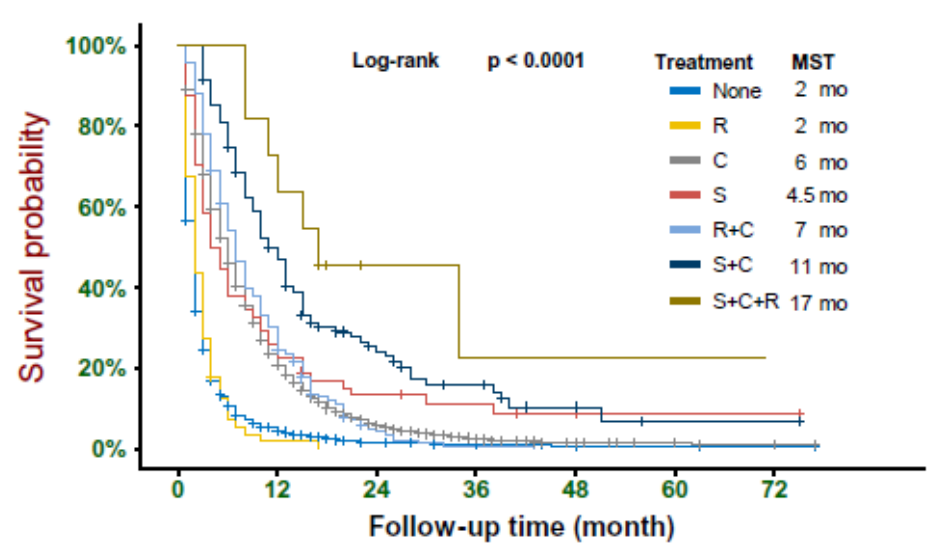

B Kaplan-Meier Curve for css

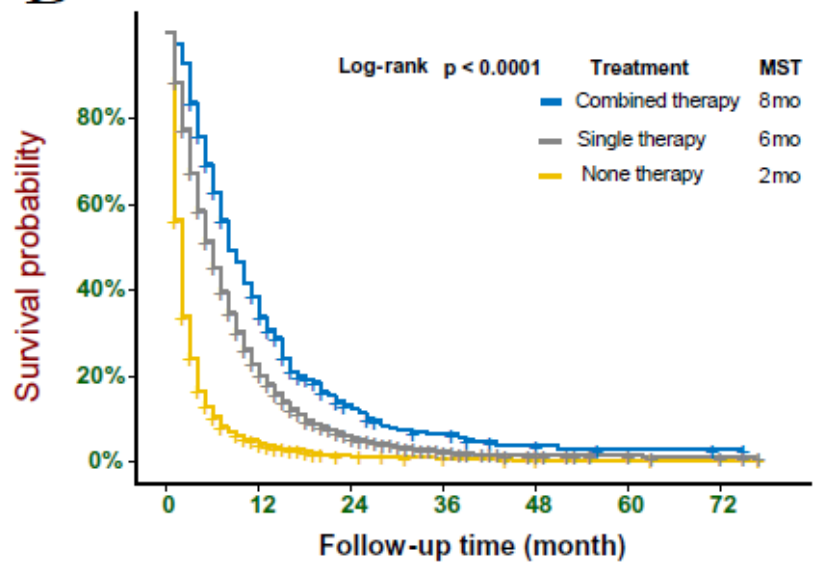

Figure 6

A-B: Kaplan-Meier curves of CSS for PCLM patients stratified by specific treatment patterns. 